\title{
A IMPORTÂNCIA DA DIFUSÃO DO CONHECIMENTO DA FERRAMENTA \\ CAR AOS DISCENTES DE AGRONOMIA
}

\begin{abstract}
ANDRÉIA COSTA DE SOUSA
Universidade Federal Rural da Amazônia (UFRA). Doutora em Ciências Agrárias com ênfase em Economia (UFRA). Mestre em Economia Rural (UFCE). Graduada em Agronomia (UFRA).

Professora Adjunta da Universidade Federal Rural da Amazônia. E-mail: andreiacostas@, hotmail.com
\end{abstract}

\section{LILIANE AFONSO DE OLIVEIRA}

Universidade Federal Rural da Amazônia. (UFRA). Doutoranda em Comunicação, Linguagens e Cultura (UFRA). Mestre em Comunicação, Linguagens e Cultura (UFRA). Graduada em Letras - Português (UFRA). Professora Auxiliar I da Universidade Federal Rural da Amazônia. ORCID: 0000-0003-4581-9952. E-mail: liliane_afonso@yahoo.com.br

\section{LUIZ AUGUSTO SILVA DE SOUSA}

Doutor em Ciências Agrárias (2011) pela Universidade Federal Rural da Amazônia, mestrado em Botânica pela Universidade Federal Rural da Amazônia (2006) e graduação em Agronomia pela Universidade Federal Rural da Amazônia (2002). Atualmente é professor Adjunto da Universidade Federal Rural da Amazônia. Tem experiência na área de Biologia Vegetal, Bioquímica, Agricultura Geral, Manejo de Vegetação Secundária, Sistemas Agroflorestais, Ecologia, Educação Ambiental, Gestão Ambiental, Extensão Rural e Produção de Grãos. 


\section{A IMPORTÂNCIA DA DIFUSÃO DO CONHECIMENTO DA FERRAMENTA CAR AOS DISCENTES DE AGRONOMIA}

A propagação do conhecimento acadêmico científico se dá através da dialética entre profissionais, alunos e pesquisadores. As universidades são grandes pólos de produção científica, tecnológica, histórica, artística e cultural, contudo, os compartilhamentos desses conhecimentos sofrem entraves dentro desses espaços. Este trabalho tem como objetivo investigar a difusão do conhecimento do Cadastro Ambiental Rural CAR, nas ciências agrárias, na Universidade Federal Rural da Amazônia - UFRA, tendo com parâmetro a percepção dos estudantes do último semestre do curso de Agronomia a respeito desta ferramenta, que é um instrumento que tem como objetivo de auxiliar a Administração Pública no processo de regularização ambiental de propriedades e posses rurais. O CAR apresenta-se como uma das principais ferramentas de amparo para o discente do curso de agronomia e para o produtor rural, assim, a presente investigação trata-se de uma pesquisa descritiva, de campo, de abordagem qualitativa, constituindo-se um estudo de caso. Os participantes da pesquisa foram 102 (cento e dois) alunos do último semestre dos cursos de Agronomia da UFRA que responderam ao questionário elaborado com 11 (onze) perguntas semiabertas e fechadas enviadas por email, onde manifestaram interesse em participar da pesquisa. A escolha do Curso de Agronomia deu-se pela atuação deste profissional posteriormente na área, na prestação de serviços a determinadas empresas ou instituições voltadas às agrárias. Os resultados demonstram que a maioria dos discentes entrevistados conhecem o CAR, porém não têm o conhecimento prático sobre a ferramenta dentro do curso refletindo um déficit na formação desses discentes para o mercado de trabalho, visto que o Cadastro Ambiental Rural é de suma importância para a vida do produtor.

Palavras-chave: Cadastro Ambiental Rural. Agronomia. UFRA. Perfil dos estudantes.

\section{THE IMPORTANCE OF DISSEMINATING KNOWLEDGE OF THE CAR TOOL TO STUDENTS OF AGRONOMY}

The propagation of academic scientific knowledge occurs through the dialectic between professionals, students and researchers. Universities are major centers of scientific, technological, historical, artistic and cultural production, however, the sharing of this knowledge is hampered within these spaces. This work aims to investigate the dissemination of knowledge of the Rural Environmental Registry - CAR, in the agrarian sciences, at the Federal Rural University of the Amazon - UFRA, taking as a parameter the perception of students in the last semester of the Agronomy course regarding this tool, which it is an instrument that aims to assist the Public Administration in the process of environmental regularization of rural properties and possessions. The CAR presents itself as one of the main support tools for the student of the agronomy course and for the rural producer, thus, the present investigation is a descriptive, field research, with a qualitative approach, constituting a study case. The research participants were 102 (one hundred and two) students from the last semester of the Agronomy courses at UFRA who answered the questionnaire prepared with 11 (eleven) semi-open and closed questions sent by email, where they expressed interest in participating in the research. The choice of the Agronomy Course was due to the 
performance of this professional later in the area, in the provision of services to certain companies or institutions aimed at agrarian organizations. The results demonstrate that most of the interviewed students know the CAR, but they do not have the practical knowledge about the tool within the course, reflecting a deficit in the training of these students for the job market, since the Rural Environmental Registry is of paramount importance for the producer life.

Keywords: Rural Environmental Registry. Agronomy. UFRA. Student profile.

\section{LA IMPORTANCIA DE DIFUNDIR EL CONOCIMIENTO DE LA HERRAMIENTA CAR A LOS ESTUDIANTES DE AGRONOMÍA}

La propagación del conocimiento científico académico se produce a través de la dialéctica entre profesionales, estudiantes e investigadores. Las universidades son los principales centros de producción científica, tecnológica, histórica, artística y cultural, sin embargo, el intercambio de este conocimiento se ve obstaculizado dentro de estos espacios. Este trabajo tiene como objetivo investigar la difusión del conocimiento del Registro Ambiental Rural - CAR, en las ciencias agrarias, en la Universidad Federal Rural del Amazonas - UFRA, tomando como parámetro la percepción de los estudiantes en el último semestre del curso de Agronomía con respecto a esta herramienta, que Es un instrumento que tiene como objetivo ayudar a la Administración Pública en el proceso de regularización ambiental de las propiedades y posesiones rurales. El CAR se presenta como una de las principales herramientas de apoyo para el estudiante del curso de agronomía y para el productor rural, por lo tanto, la presente investigación es una investigación de campo descriptiva, con un enfoque cualitativo, que constituye un estudio caso. Los participantes de la investigación fueron 102 (ciento dos) estudiantes del último semestre de los cursos de Agronomía en UFRA que respondieron el cuestionario preparado con 11 (once) preguntas semiabiertas y cerradas enviadas por correo electrónico, donde expresaron interés en participar en la investigación. La elección del Curso de Agronomía se debió al desempeño de este profesional más adelante en el área, en la prestación de servicios a ciertas empresas o instituciones dirigidas a organizaciones agrarias. Los resultados demuestran que la mayoría de los estudiantes entrevistados conocen el CAR, pero no tienen el conocimiento práctico sobre la herramienta dentro del curso, lo que refleja un déficit en la capacitación de estos estudiantes para el mercado laboral, ya que el Registro Ambiental Rural es de suma importancia para el La vida del productor.

Palabras clave: Registro Ambiental Rural. Agronomía UFRA Perfil de estudiante. 


\section{A IMPORTÂNCIA DA DIFUSÃO DO CONHECIMENTO DA FERRAMENTA CAR AOS DISCENTES DE AGRONOMIA}

\section{Introdução}

A difusão do conhecimento na comunidade acadêmica se dá através da dialética e socialização comunicativa que contribuem para o saber científico, sendo necessária uma relação recíproca entre profissionais, alunos e pesquisadores para que o conhecimento seja disseminado nos diferentes setores (Andrade; Ribeiro; Pereira, 2009). De maneira geral, a difusão é vista como um processo de comunicação de informações, tecnologias, conhecimentos e inovações para um determinado público alvo (Gastal, 1986).

No entanto, um dos problemas que impedem essa difusão do saber científico seria de caráter cultural, pois muitas vezes a informação não é repassada pelos indivíduos na sociedade acadêmica, já que estes visam suas carreiras acima do saber. Em uma sociedade onde certas práticas se encontram enraizadas, o compartilhamento do conhecimento sofre entraves. Isso sé dá, por vezes, devido à luta por poder, visto que o conhecimento e publicações geram prestígio no meio acadêmico (Machado, 2005). Outro problema que vêm a impedir no compartilhamento de informações também é a insuficiência das mesmas ou a não confiabilidade nestas, o que vem a prejudicar o processo de difusão do saber (Andrade et al., 2009).

As universidades são grandes pólos de produção científica, tecnológica, histórica, artística e cultural. Com isso, visamos neste presente artigo usá-la como campo de estudo, pois, para entender o processo de difusão do conhecimento da ferramenta Cadastro Ambiental Rural (CAR) para os estudantes de Agronomia da Universidade Federal Rural da Amazônia, no campus Belém, no estado do Pará, faz-se necessário entender como este conhecimento chega aos alunos, seja através de professores, mídias e/ou demais setores da sociedade. A escolha desse lócus de pesquisa, a Universidade Federal Rural da Amazônia para este entendimento do assunto, fez-se devido à observação de sua importância na produção e/ou contribuição da produção do conhecimento em si.

As universidades vivenciam múltiplos desafios colocados tanto pela sociedade, quanto pelo Estado. Estes desafios ou crises, dizem respeito ao questionamento da sua hegemonia na produção 
de conhecimento e de sua legitimidade. A crise das universidades está também, segundo Buarque (1994, p. 225), "em muitos casos, na perda da capacidade para definir corretamente os problemas aos quais a formação e as pesquisas devem servir" ou seja, para que, para quem e como devemos produzir e difundir conhecimento (Castro, 2004).

Neste diapasão, a presente pesquisa procurou investigar a difusão do conhecimento do CAR, nas ciências agrárias, na Universidade Federal Rural da Amazônia, tendo com parâmetro a percepção dos estudantes do último semestre do curso de agronomia a respeito desta ferramenta, que é um instrumento que tem como objetivo de auxiliar a Administração Pública no processo de regularização ambiental de propriedades e posses rurais.

Assim, a Lei n ${ }^{\circ}$ 12.651/2012 no âmbito do Sistema Nacional de Informação sobre Meio Ambiente - SINIMA, criou o Cadastro Ambiental Rural ou CAR. Trata-se de um registro eletrônico, obrigatório para todos os imóveis rurais, que tem por finalidade integrar as informações ambientais referentes à situação das Áreas de Preservação Permanente, das áreas de Reserva Legal, das florestas e dos remanescentes de vegetação nativa, das Áreas de Uso Restrito (pantanais e planícies pantaneiras) e das áreas consolidadas das propriedades e posses rurais do país.

\section{Metodologia}

A presente investigação decorre de uma pesquisa descritiva, de campo, de abordagem qualitativa, constituindo-se de um estudo de caso. Os participantes da pesquisa foram 102 (cento e dois) alunos do último semestre dos cursos de Agronomia da Universidade Federal Rural da Amazônia.

A quantidade da amostra mostrou-se satisfatória uma vez que este quantitativo é a média expressa de formandos do curso de Agronomia ao ano para o campus de Belém, na modalidade extensiva, selecionados por meio das notas obtidas pelo Exame Nacional do Ensino Médio (ENEM), na qual são ofertadas 150 (cento e cinquenta) vagas para entrada anual. E nesta fase do curso, em que ocorreu a pesquisa, os alunos já concluíram quase $90 \%$ de suas obrigações com as disciplinas obrigatórias e eletivas, tendo, portanto, condições de avaliar seus conhecimentos a respeito da necessidade do conhecimento da ferramenta CAR.

A escolha do Curso de Agronomia deu-se pela atuação deste profissional posteriormente na área, na prestação de serviços a determinadas empresas ou instituições voltadas às agrárias.

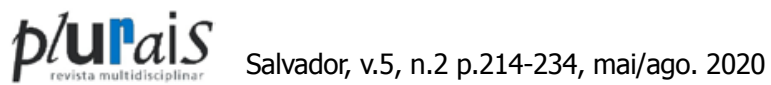


Em seus 50 anos de existência, a Universidade Federal Rural da Amazônia (UFRA), lócus desta pesquisa, destaca-se na Amazônia por ter prestado relevantes serviços à região amazônica, em especial à formação de milhares de profissionais em Ciências Agrárias, incluindo estrangeiros de mais de 15 países.

Os entrevistados foram devidamente esclarecidos verbalmente em salas de aula sobre os objetivos e metodologia da pesquisa. Após os esclarecimentos, os entrevistados responderam o questionário com 11 (onze) perguntas semiabertas e fechadas enviadas por email, onde manifestavam seu interesse em participar da pesquisa. Desta forma tiveram também assegurados, os direitos de sigilo de identidade e de voluntariado na pesquisa identificados como base quantitativa e, suas informações foram descritas e, posteriormente, transferidas ao programa Microsoft Excel, para assim ser realizado a análise descritiva dos dados para a elaboração dos gráficos e tabelas.

\section{A geração e difusão do conhecimento como componentes de um processo}

A noção de conhecimento está e esteve intimamente ligada ao estágio de evolução em que se encontram as sociedades em suas diversas épocas, modificando esse estágio e sendo por ele modificada. Na medida em que a concepção de conhecimento sofre alterações no decorrer do tempo, o próprio conteúdo do conhecimento vai sendo modificado, substituído e adicionado sob várias formas. Mas afinal o que vem a ser conhecimento? (Guedes; Duarte, 2000).

De acordo com Marconi e Lakatos (2005) existem quatro tipos de conhecimento: o popular, o filosófico, o religioso e o científico. Neste estudo, focamos nossas análises no conhecimento científico. Mendonça et al., (2003) afirmam que o conhecimento científico é obtido de maneira planejada, ordenada e controlada, por meio de teorias objetivas, com métodos e técnicas específicas, para que se permita a verificação da sua validade. Esse conhecimento é registrado em uma linguagem rigorosa, possibilitando a sua transmissão e ampla utilização, sendo este o tipo de conhecimento mais utilizado nos meios acadêmicos.

Destarte, como o conhecimento e a tecnologia em si não são neutros, ou seja, eles possuem um lado técnico e outro social; várias consequências sociais da aplicação tecnológica pelo setor produtivo serão geradas. É, portanto, esta característica de não neutralidade que torna indispensável o relacionamento e o diálogo entre os seus produtores (pesquisadores), os seus divulgadores (extensionistas) e os seus adotantes (produtores agropecuários) (SOUSA, 1988). 
A difusão do conhecimento, principalmente no que tange os cursos de agronomia, sempre esteve a cargo de empresas públicas de extensão rural, isto é, as universidades produzem o conhecimento e essas instituições o difundem. Presentemente, as próprias universidades têm difundido o conhecimento ali produzido por meio da chamada de extensão universitária. Contudo, ainda existem parcerias entre as universidades e as empresas de assistência técnica e extensão rural.

Cabe salientar também que a disseminação do conhecimento se qualifica de acordo com os meios. Segundo Fujino (2019) ocorre a conversão da informação em conhecimento, quando o indivíduo busca informações com um propósito definido, na tentativa de encontrar algo que possibilite alterar o seu nível de conhecimento, seleciona e processa a informação e, neste processo muda a capacidade de conferir sentido, experiência, criando significados.

A organização do conhecimento como uma organização capacitada, organiza seus recursos e capacidades, transformando a informação em compreensão e insights, e disponibilizando esse conhecimento por meio de iniciativas e ações, de modo a aprender a se adaptar a seu ambiente mutável. Choo (2006) entende que a função primordial da administração da informação é garantir que as necessidades de informação dos membros da organização sejam atendidas com uma mistura equilibrada de produtos e serviços.

Variados são os meios de comunicação utilizados para viabilizar a difusão e a transferência de conhecimento, tais como: dia de campo, unidade demonstrativa, unidade de observação, curso, demonstração de resultados, treinamento, reuniões, demonstração de métodos, exposição em rádio e televisão, publicação em periódicos, dentre outros (Franco, 2009).

A função da difusão é antes de tudo educativa, pois tende a produzir mudanças nos conhecimentos, atitudes e destrezas das pessoas, para que possam conseguir o desenvolvimento tanto individual quanto social.

Desse modo, deve-se entender a ideia da geração e difusão do conhecimento como componentes de um processo, que começa com o produtor, diagnosticando os problemas a serem pesquisados, posteriormente, passa pela experimentação; prossegue com teste da tecnologia gerada e conclui-se com a incorporação de tecnologia aos sistemas de produção em uso pelos produtores rurais (Carneiro et al., 2009).

\section{p/ullais salvador, v.5, n.2 p.214-234, mai/ago. 2020}




\section{A ferramenta CAR}

O CAR é uma das principais ferramentas de amparo para o discente do curso de agronomia e para o produtor rural. O cadastro pode ser preenchido no site www.car.gov.br ou nos sites dos órgãos estaduais que utilizam sistema próprio integrado ao Sistema Nacional de Cadastro Ambiental Rural (Sicar). O Poder Público oferece suporte técnico para a inscrição dos imóveis até 4 módulos fiscais (medida que varia de acordo com o município). Para os assentados da reforma agrária, esse suporte é fornecido pelo Instituto Nacional de Colonização e Reforma Agrária (Incra).

O CAR foi instituído pelo Código Florestal Brasileiro, Lei $N^{\circ} 12.651 / 2012$ e é um registro georeferrenciado das informações ambientais das propriedades e posses rurais do país. De acordo com o Novo Código Florestal, as multas referentes ao desmatamento ilegal ocorridas antes de 2008 foram absolvidas, ocasionando a redução de mata nativa a ser restaurada. Nesse período, foi criado o CAR para que houvesse a verificação do cumprimento da lei, a fim de garantir o beneficiamento da anistia aos produtores.

O CAR caracteriza-se como uma ferramenta de registro eletrônico obrigatório para todos os imóveis rurais, possui a funcionalidade de integrar os dados para o devido controle, monitoramento e combate ao desmatamento da mata nativa do Brasil, assim como auxilia na organização do imóvel rural na questão ambiental e econômica. O Serviço Florestal Brasileiro (SFB) possui a responsabilidade no âmbito federal de "apoiar a implantação, gerir e integrar as bases de dados ambientais do CAR junto aos Órgãos de Meio Ambiente Estaduais (OEMAs) e outras organizações em todo o território nacional" (AMBIENTE, 2019).

O CAR baseia-se na coleta de informações da propriedade rural, incluindo informações da identificação do proprietário; da propriedade ou posse rural; identificação do perímetro do imóvel; das áreas de remanescente de vegetação nativa, das Áreas de Preservação Permanente (APP) e de Reserva Legal (RL), das áreas de uso restrito e consolidadas (BRASIL, 2012a; BRASIL, 2016).

A inscrição no CAR considera: dados do proprietário, possuidor rural ou responsável direto pelo imóvel rural; dados sobre os documentos de comprovação de propriedade e ou posse; e informações georreferenciadas do perímetro do imóvel, das áreas de interesse social e das áreas de utilidade pública, com a informação da localização dos remanescentes de vegetação nativa, 
das Áreas de Preservação Permanente, das áreas de Uso Restrito, das áreas consolidadas e das Reservas Legais.

Sabemos que para a proteção e segurança da fauna e flora de cada região é necessária a conservação das florestas e também dos outros tipos de vegetação. Segundo Laudares; Silva; Borges (2014) a legislação brasileira contém dentre os principais instrumentos para assegurar essa conservação, a APP e a RL.

As APP's correspondem às áreas protegidas, cobertas ou não por vegetação nativa, com a função ambiental de preservar os recursos hídricos, a paisagem, a estabilidade geológica e a biodiversidade, facilitar o fluxo gênico de fauna e flora, proteger o solo e assegurar o bem-estar das populações humanas.

Laudares; Silva; Borges (2014) ponderam que o Brasil é um dos países pioneiros em relação as leis que tratam do meio ambiente, é possível observar um grande progresso do país no que tange a preservação do meio ambiente, mas que também ainda há um caminho longo a ser seguido. Segundo Gomes e Martinelli (2012) o Código Florestal de 1965 apresenta falhas e uma forte ineficácia no que diz respeito ao monitoramento e regulamentação da extinção de florestas e componentes da natureza.

Seguindo a premissa da ineficácia do Código Florestal de 1965 (Gomes; Martinelli, 2012) torna-se necessária uma forma de sanar as falhas da aplicação do Código Florestal. Então, criou-se o novo Código Florestal que foi sancionado em 2012 sob a Lei Federal n ${ }^{\circ} 12.651$ que

visa facilitar a relação do produtor agrícola com a preservação do meio ambiente por meio das delimitações de Áreas de Preservação Permanente e Reservas Legais. Possibilitou então a flexibilidade dos critérios de proteção, essenciais para o entendimento dos decretos.

O CAR constitui uma "base de dados estratégica para o controle, o monitoramento e o combate ao desmatamento das florestas e demais formas de vegetação nativa do Brasil" (Laudares; Silva; Borges 2014, p. 2).

Laudares, Silva; Borges (2012) citam que todas as informações referentes à situação ambiental das áreas de preservação permanente, das áreas de reserva legal, das florestas e dos remanescentes de vegetação nativa, das áreas de uso Restrito e das áreas consolidadas das propriedades e posses

\section{p/ullais salvador, v.5, n.2 p.214-234, mai/ago. 2020}


rurais do país irão compor uma base de dados integrada, com fotos de satélites, disponíveis a toda população o que então pode-se dizer que o CAR surge como uma possibilidade de fomento para a formação de corredores ecológicos e para a conservação dos demais recursos naturais, o que contribui para a melhoria da qualidade ambiental.

\section{Resultados e discussão: análise do perfil dos estudantes entrevistados}

A pesquisa compõe o perfil e requisitos direcionados a percepção do discente diante da difusão do conhecimento da plataforma do CAR. Na Tabela 1 estão contidas as principais características correlacionadas ao perfil dos discentes. A partir da Tabela 1 podemos observar que dentre os entrevistados da pesquisa, apresentou-se a frequência relativa entre homens $(46 \%)$ e mulheres $(54 \%)$, o que podemos considerar uma frequência semelhante.

Esses dados também ocorrem no relatório divulgado pela Pró-Reitoria de Planejamento e Desenvolvimento Institucional (PROPLADI/UFRA, 2014), a predominância entre homens (41,5\%) e mulheres $(58,5 \%)$ é semelhante, em uma amostra com 591 estudantes (SANTANA, 2015). Observou-se nesta pesquisa uma crescente inserção da mulher no nível superior da região. Isso pode ser reflexo direto do cenário atual das Instituições de Ensino Superior (IES) brasileiras onde os Dados do Censo da Educação Superior de 2016, última edição do levantamento, revelam que as mulheres representam $57,2 \%$ dos estudantes matriculados em cursos de graduação. No Censo da Educação Superior de 2006, as mulheres representavam 56,4\% das matrículas em cursos de graduação (INEP, 2006).

Tabela 1. Perfil dos discentes entrevistados do curso de Agronomia do campus da UFRA/Belém.

\begin{tabular}{r|l}
\hline \multicolumn{1}{|c|}{ Variável } & \multicolumn{1}{c}{$\%$} \\
Sexo & $54 \%$ feminino e $46 \%$ masculino \\
Idade & 20 a 56 anos \\
Média da idade & 25 anos \\
Residem em Belém & $73 \%$ \\
Contato com o meio rural & $90 \%$ \\
\hline
\end{tabular}

Fonte: Resultados da pesquisa (2019) 
Percebe-se, no que se refere à idade dos discentes, que varia entre 20 a 56 anos, possuindo idade média de 25 anos. Ao analisarmos o Gráfico 1 abaixo, constata-se o intervalo de faixa etária com maior expressão que foi entre 20 e 24 anos (59\%), seguido do intervalo de idade subsequente 25 a 29 anos (31\%). Uma amplitude de idade bem distante e diferente de outras universidades comparada a Finatti et al (2007) que constaram que na Universidade Estadual de Londrina 86,7\% dos alunos da graduação tinham idade até 26 anos. Costa et al. (2010) realizaram uma pesquisa entre os alunos de Odontologia da Universidade Estadual de Montes Claros, e verificaram que a idade dos alunos variou entre 18 e 27 anos, sendo 22 a média e variação de $21 \%$ com 21 anos. Ademais, na pesquisa nacional feita pelo Fonaprace (2010) isso se confirma também, pois, 75\% dos discentes brasileiros são jovens com idade entre 18 e 24 anos, observou-se que a média de idade foi 23 anos, porém a maior concentração de estudantes encontra-se na faixa de 21 anos. $\mathrm{O}$ Censo da educação superior de 2015 aduz que a idade média dos alunos matriculados em cursos presenciais em IES brasileiras é de 26 anos (CENSO 2015).

Gráfico 1 - Faixa etária dos alunos entrevistados de Agronomia (cursando o $10^{\circ}$ semestre)

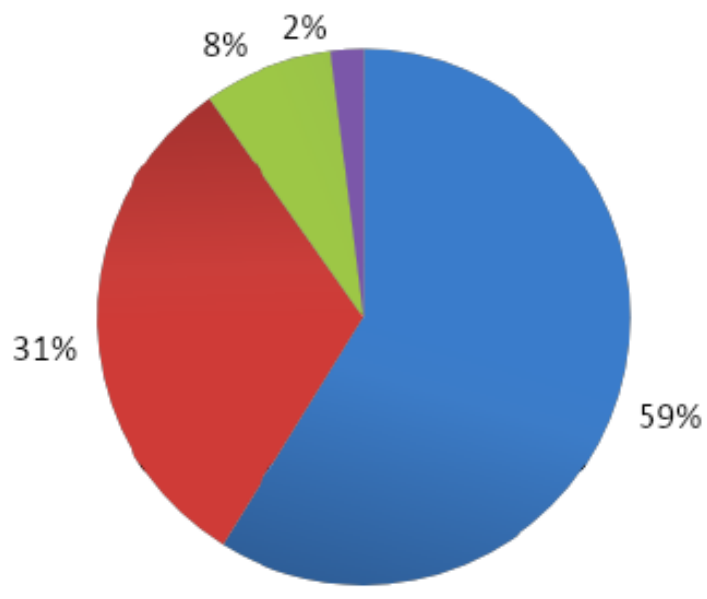

De 20 a 24 anos

De 25 a 29 anos

De 30 a 34

A partir de 35

Fonte: Dados da Pesquisa, 2019

Quanto ao local de moradia dos discentes constatou-se que 73\% dos discentes participantes da pesquisa residem em Belém, o que pode facilitar o acesso aos estudantes à universidade. Em 
contrapartida, $27 \%$ dos discentes não residem na capital, assim, deduz-se que esses estudantes possam residir em cidades vizinhas pertencentes à região metropolitana e nos distritos pertencentes a capital. Por certo, os mesmos precisam se deslocar, diariamente, à Universidade e em sua maioria com recursos próprios. Sendo assim, entra o papel da Universidade através da Pró-reitoria de Assuntos Estudantis cuja missão é desenvolver ações institucionais para viabilizar o acesso, permanência e conclusão exitosa dos discentes dos cursos de graduação. $\mathrm{O}$ alcance desta missão está pautado no esforço de assegurar igualdade de oportunidades e oferecer a estrutura de apoio ao desempenho acadêmico, pessoal, social, emocional e profissional dos estudantes, de acordo com os princípios e diretrizes contidos no Plano Nacional de Assistência Estudantil (PNAES), que se traduz em condição necessária para viabilizar a política do MEC de expansão das Instituições Federais de Ensino Superior (SANTANA 2015).

Cabe ressaltar que mesmo com uma porcentagem considerável de discentes residindo na capital de Belém (73\%), podemos observar que 90\% do total dos estudantes afirma ter contato com meio rural. É muito importante que esses discentes possuam um convívio com o campo, pois estudam na capital em um curso que possui essa necessidade, o conhecimento ao meio rural. Visto que o contato com a realidade proporciona para o indivíduo, seja ele educador; pesquisador ou educando, uma intervenção social, uma produção de conhecimento que envolve um saber coletivo, não se resume apenas no ato de transmitir e receber e sim envolve uma prática social e a construção do conhecimento (JEZINE, 2006).

\section{Os discentes entrevistados e o contato com o meio rural}

Dos discentes entrevistados que relataram ter contato com o meio rural $(90 \%)$, foi questionado a forma que esse contato se sucede. Na Tabela 2 é possível observar que o maior contato foi através de férias na casa de parentes $(43 \%)$ e por seguinte por meio de alguma atividade da universidade através de aulas práticas (19\%), estágio (16\%) e visitas técnicas (14\%). Poucos residem no meio rural (2\%), apesar de possuir parentes ou até mesmo os pais residirem e possuírem negócios envolvidos no meio conforme descrito abaixo. 
Tabela 2. Forma de contato com o meio rural dos discentes entrevistados do curso de Agronomia do campus da UFRA/Belém.

\begin{tabular}{r|l}
\hline Formas de contato com o meio rural & $\%$ \\
\hline Férias na casa de parentes & 43 \\
Aulas práticas & 19 \\
Estágio & 16 \\
Visitas técnicas & 14 \\
Trabalho & 3 \\
Reside no meio rural & 3 \\
Bolsa de estudos & 2 \\
\hline Fonte: Dados da pesquisa (2019) &
\end{tabular}

Os discentes que tem o contato com o meio rural através da casa dos pais e parentes devem ter um contato mais frequente por conta da facilidade ao acesso a esse meio, e isso contribui positivamente na sua jornada acadêmica com a fácil compreensão dos assuntos abordados nas disciplinas.

Para que se compreendam as representações que os jovens constroem sobre a vida acadêmica e o futuro profissional é necessário analisá-las como elementos afetivos, mentais e sociais, levando em consideração as relações sociais que tendem a afetá-las, bem como a realidade material, social e ideativa sobre a qual elas têm de intervir (JODELET; 2001).

Por isso a importância da Universidade fazer essa aproximação do discente com as atividades que cercam o curso de agronomia, sejam por meio de aulas expositivas, aulas práticas, visitas técnicas e projetos de pesquisa e extensão universitária. De acordo com Jodelet (2001), as representações sociais se manifestam como uma forma de conhecimento desenvolvida pelos indivíduos e pelas sociedades para construir sua visão em relação a objetos, situações e contextos aos quais estão articuladas. 


\section{O conhecimento do CAR}

Os entrevistados ao serem questionados se já teriam ouvido falar da ferramenta do CAR, $99 \%$ dos alunos entrevistados afirmaram positivamente tomar conhecimento da sua existência. Esse resultado é bastante favorável, visto que essa plataforma é essencial na regularização e fiscalização dos imóveis rurais após o a aprovação do novo código florestal brasileiro. Além do que, o CAR é apontado por especialistas como o instrumento capaz de permitir que o poder público gerencie os recursos florestais, ao proporcionar não só o cruzamento entre as informações de desmatamento e as áreas constantes do CAR, mas a conciliação entre as atividades produtivas e a conservação ambiental, de forma especialmente ágil e rápida (Pires, 2013).

Contudo, o meio em que os discentes entrevistados ouviram falar e tomaram conhecimento da existência do CAR foi por meio das aulas ministradas na universidade (66\%) em seguida através de cursos $(23 \%)$, palestras ( $7 \%$ ) e estágio ou trabalho (4\%), conforme apresentados na Tabela 3. Através destes dados podemos notar a grande importância e responsabilidade da Universidade em repassar conhecimentos e atualizações a respeito de assuntos relacionados ao exercício dessa importante ferramenta na formação desse profissional.

Tabela 3 - Meios de conhecimento do CAR

\begin{tabular}{r|l} 
Meio de conhecimento & $\%$ \\
\hline Aulas & 66 \\
Cursos & 23 \\
Palestras & 7 \\
Estágio ou trabalho & 4 \\
\hline Fonte: Dados da pesquisa (2019) & \multicolumn{1}{|l}{}
\end{tabular}


Segundo Santos (2008, p. 64) as aulas são uma das principais formas de aprendizagem, no entanto, o professor precisa atuar como mediador entre o aluno e o conhecimento. Para tanto, a atuação do professor deve levar em conta que o aluno é o sujeito do conhecimento e não mero receptor de informações. Podemos considerar válido todo o esforço no sentido de envolver os alunos, tornando as aulas momentos de interação e aprendizagem, pois a difusão de todo e qualquer conhecimento gerado é condição primordial para o desenvolvimento do público que necessita dessas inovações (Sousa, 2001; Thiollent, 1984).

Para Cezar et al., (2000), o fato de repassar uma informação sob diferentes formas não significa que a comunicação esteja acontecendo, pois a condição mais importante para ocorrer comunicação é estabelecer um campo comum de interesses por meio de diálogo entre as partes. Para isso, a extensão rural torna-se uma metodologia utilizada para difundir algum conhecimento ou tecnologia, por meio do enfoque participativo. Por participação, pode-se entender como a oportunidade dada às pessoas de expressar livremente seus pontos de vistas e agregar experiências, conhecimentos e demandas na formulação de políticas e decisões que as envolvem.

Dos alunos entrevistados, todos concordam que a ferramenta é importante para sua formação profissional, tanto para conhecimento técnico (55\%), quanto para consultoria (44\%) e concursos públicos $(1 \%)$, conforme exposto na Tabela 4 . A ferramenta CAR apresenta-se de extrema importância hoje, pois traz muitos benefícios ao produtor rural.

Tabela 4 - Importância do CAR

\begin{tabular}{r|l}
\hline Importância do CAR & \% \\
\hline Conhecimento técnico & 55 \\
Consultoria & 44 \\
Concurso público & 1 \\
\hline Fonte: Dados da pesquisa (2019) &
\end{tabular}


Laudares; Silva; Borges (2014) reforçam que o CAR tem a pretensão de se tornar uma base de dados estratégica para integrar as informações ambientais das áreas rurais, com o intuito de auxiliar a recuperação de áreas degradadas, promover o controle e combate ao desmatamento. Assim, é preciso analisar que o processo de registro e o mapeamento das áreas apresentam falhas e erros acumulativos que potencializam o fracasso da ferramenta para com o objetivo a que se propõe. Por essa razão a significativa responsabilidade da formação de profissionais qualificados para o uso deste serviço.

\section{O papel da universidade na formação desses profissionais}

A respeito da formação de profissionais agrônomos preparados para o mercado de trabalho em relação à utilização da plataforma do CAR, foi questionado aos discentes entrevistados se a universidade prepara seus alunos para o uso da plataforma, tal como costa no Gráfico 3. Dos entrevistados, $87 \%$ afirmaram que o conhecimento sobre a plataforma, no ensino superior, não foi o suficiente para lhe preparar para o futuro mercado de trabalho. Em outros estudos, este sentimento de concluintes de curso não se sentirem preparados para o mercado de trabalho é comum. De acordo com Gondim (2002), o que parece ser um sentimento geral dos formandos, com raras exceções, é que a formação universitária é insuficiente para atender à demanda requerida no mercado de trabalho.

Gráfico 2 - O conhecimento do CAR no ensino superior foi o suficiente para o futuro mercado de trabalho.

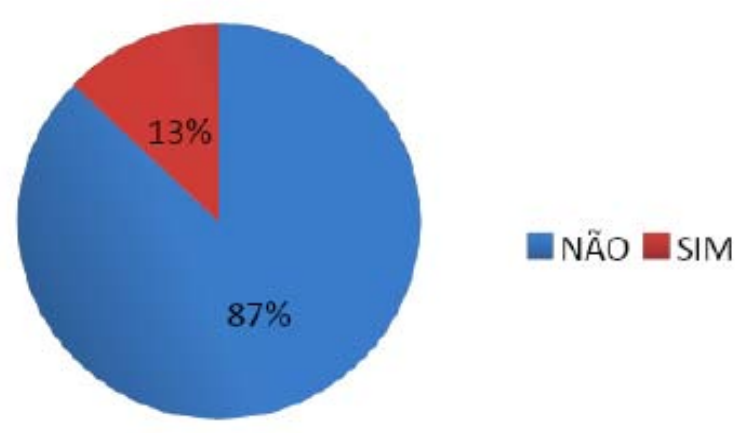

Fonte: Dados da Pesquisa, 2019

O desenvolvimento científico e tecnológico, suporte fundamental da globalização, aumenta a complexidade do mundo e passa a exigir um profissional com competência para lidar com um número expressivo de fatores. 
Este perfil profissional desejável está alicerçado em três grandes grupos de habilidades:

i) as cognitivas, comumente obtidas no processo de educação formal (raciocínio lógico e abstrato, resolução de problemas, criatividade, capacidade de compreensão, julgamento crítico e conhecimento geral); ii) as técnicas especializadas (informática, língua estrangeira, operação de equipamentos e processos de trabalho) e iii) as comportamentais e atitudinais - cooperação, iniciativa, empreendedorismo (como traço psicológico e como a habilidade pessoal de gerar rendas alternativas que não as oferecidas pelo mercado formal de trabalho, motivação, responsabilidade, participação, disciplina, ética e a atitude permanente de aprender a aprende. (GONDIM, 2002, p. 305).

No Gráfico 3 é possível observar que os entrevistados apontaram a ausência de aulas práticas (84\%) como o principal motivo que interfere na eficiência do ensino superior. As aulas práticas ajudam os alunos no processo de interação, na apropriação e no desenvolvimento de conceitos científicos. Permitem que os estudantes aprendam a abordar objetivamente o seu mundo e a desenvolver saídas para situações que envolvam muitas variáveis.

Desta forma, partindo da hipótese de que as aulas práticas possuem potencial pedagógico na aquisição do conhecimento científico pelos alunos, Rauber (2008) aponta que esta aproximação é eficiente para trocar os conhecimentos entre docentes estudantes-comunidade pela possibilidade de desenvolvimento de processos ensino-aprendizagem a partir de práticas cotidianas.

Gráfico 3 - O que falta para o conhecimento do ensino superior ser eficiente

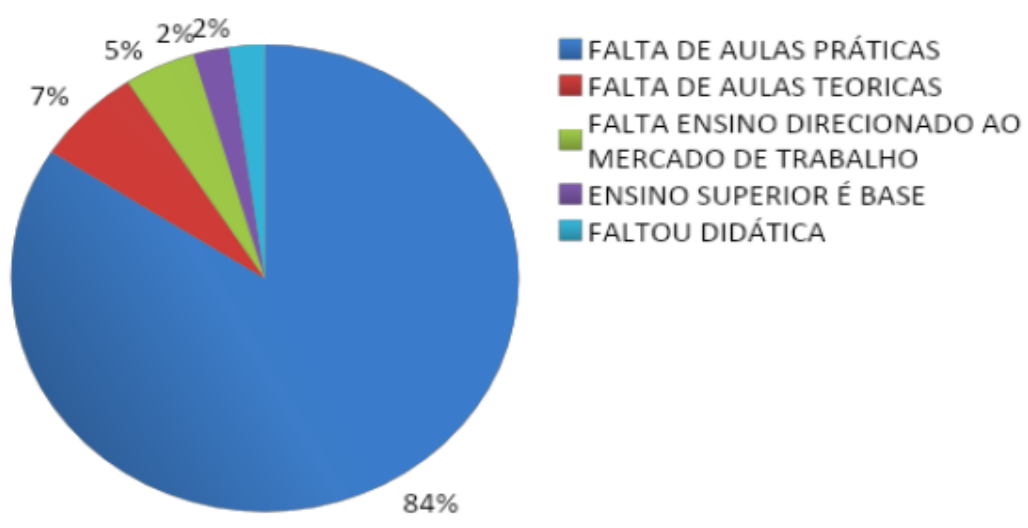

Fonte: Dados da Pesquisa, 2019.
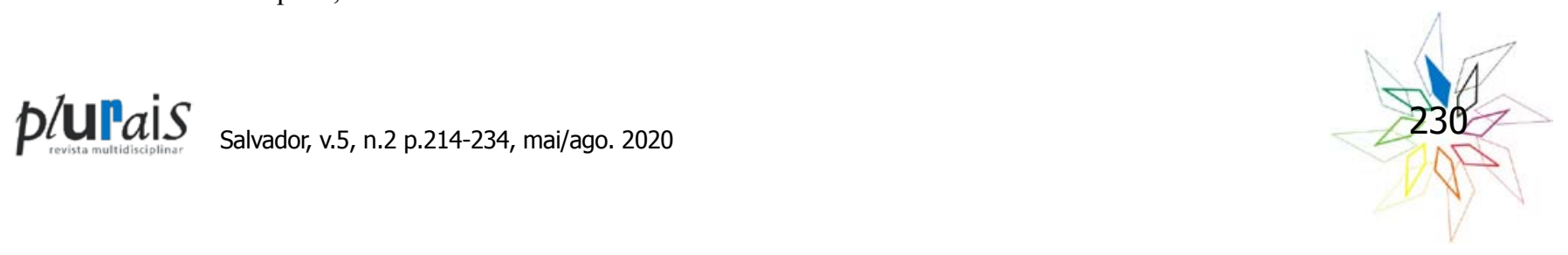
Constatou-se que apenas 7\% dos entrevistados apontaram para a falta de aulas teóricas. Para Gondim (2002), formação teórica apresenta-se como inadequada por duas razões principais: "há um descompasso entre o curso básico e o profissionalizante e, no caso das disciplinas profissionalizantes, os professores não têm a experiência necessária para oferecer modelos práticos derivados das teorias estudadas e analisadas no curso". Segundo Rezende (2012), as instituições de ensino superior destinadas à formação de discentes de ciências agrárias fundamentam-se em propostas curriculares baseadas na divisão disciplinar, produzindo uma concepção fragmentada e técnica.

Entretanto, Pimenta (1995, p. 61) afirma que educação é prática social que ocorre nas diversas instâncias da sociedade. Conforme a autora, em sua reflexão sobre o ensino teórico e a prática na aprendizagem, a atividade teórica possibilita de um modo indissociável o conhecimento da realidade e estabelece as finalidades para sua transformação. Porém, para tal transformação somente a atividade teórica não será suficiente, é necessário atuar na prática.

Deste modo, para conhecer é necessário lançar mão de vários recursos, já que o conhecimento não é adquirido somente "contemplando" ou "olhando", ele é adquirido com os indivíduos interagindo com a realidade em estudo, em uma interação.

\section{Considerações finais}

Neste diapasão, observou-se que a maioria dos alunos entrevistados, concluintes do curso de agronomia da Universidade Federal Rural da Amazônia, conhecem o CAR, porém não têm o conhecimento prático sobre a ferramenta, apresentando-se como um empecilho para a difusão do conhecimento sobre o Cadastro Ambiental Rural dentro do curso.

Os dados apresentados refletem um déficit na formação desses discentes para o mercado de trabalho, visto que o Cadastro Ambiental Rural é de suma importância para a vida do produtor e este profissional agrônomo pode se especializar no preenchimento deste Cadastro Ambiental Rural (CAR) auxiliando o produtor a exemplo, para a obtenção de crédito agrícola, em todas as suas modalidades, conquistando uma redução nas taxas de juros, além de proporcionar limites e prazos maiores quando comparados a produtores que não possuem o cadastro e fazem uso de outras opções disponíveis no mercado.

\section{REFERÊNCIAS}

ANDRADE, Maria Teresinha Tamanini; PEREIRA, Hernane Borges de Barros; RIBEIRO, Núbia Moura. Um estudo sobre a difusão e o compartilhamento do conhecimento na cultura acadê- 
mica. In: IX Congreso ISKO-España, 2009, Valencia. Actas del IX Congreso ISKO-España. Valencia, 2009. v. II. p. 973-985.

ASSOCIAÇÃO NACIONAL DOS DIRIGENTES DAS INSTITUIÇÕES FEDERAIS DE ENSINO SUPERIOR (ANDIFES). Perfil socioeconômico e cultural dos estudantes de graduação das universidades federais brasileiras. In: Fórum Nacional de Pró-Reitores de Assuntos Comunitários e Estudantis (FONAPRACE). Brasília, DF: ANDIFES, 2011.

BRASIL. Lei no 12.651, de 25 de maio de 2012. Dispõe sobre a proteção da vegetação nativa; altera as Leis no 6.938, de 31 de agosto de 1981, 9.393, de 19 de dezembro de 1996, e 11.428, de 22 de dezembro de 2006; revoga as Leis no 4.771, de 15 de setembro de 1965, e 7.754, de 14 de abril de 1989, e a Medida Provisória no 2.166-67, de 24 de agosto de 2001; e dá outras providências. Disponível em: http://www.planalto.gov.br/ccivil_03/_ato2011-2014/2012/ lei/L12651 compilado.htm. Acesso em: 01 mar 2016.

BRASIL. DESENVOLVIMENTO Rural. Ministério do Meio Ambiente. 2019. Disponível em $<$ https://www.mma.gov.br/desenvolvimento-rural/cadastro-ambiental-rural.html $>$. Acesso em: 06 de ago. de 2019.

CARNEIRO, E. F.; SILVA, N. L.; FRAXE, T. J. P. A extensão rural no médio Solimões: uma proposta interdisciplinar. 2009. 16p. Disponível em: <http://www.alasru.org/ \%20Fraxe.pdf $>$. Acesso em: 15 ago. 2019.

CÉZAR, I. M.; SKERRATT, S.; DENT, J. B. Sistema participativo de geração e transferência de tecnologia para pecuaristas: o caso aplicado à Embrapa Gado de Corte. Cadernos de Ciência \& Tecnologia, Brasília, v.17, n.2, p.135-169, maio/ago. 2000.

CHOO, C. W.The Knowing Organization: How Organizations Use Information to Construct Meaning Create Knowlwdge, and Make Decision. New York : Oxford. 2006.

FINATTI, BE; Alves, JM; Silveira, RJ. Perfil Sócio, Econômico e Cultural dos Estudantes da Universidade Estadual de Londrina - UEL - Indicadores para implantação de uma política de assistência estudantil. Revista do Programa de Pós- Graduação em Serviço Social. Juiz de Fora. 2007; 2(1): 188-206.

FONAPRACE. Assistência Estudantil - uma Questão de Investimento. Brasília: agosto de 2000. Disponível em: http://www.unb.br/administracao/decanatos/dac/fonaprace/documentos/ assist_est.html. Acesso em: 17 jul. 2012.

FRANCO, C.F.O. Dinâmica da difusão de tecnologia no sistema produtivo da agricultura brasileira. XLII Congresso da Sociedade Brasileira de Economia, Administração e Sociologia Rural - SOBER. Anais... Cuiabá - MT: SOBER, 2009.

\section{plurais}


GASTAL, E. O processo de transformação tecnológica na agricultura. Cadernos de Difusão Tecnologia, Brasília, v.3, n.1, p.155-169, jan./abr., 1986.

GOMES, D.; MARTINELLI, D. M. C. O Código Florestal e o uso da propriedade rural na perspectiva da (in)constitucionalidade da reserva legal. Cadernos de Direito, Piracicaba, 12(23), 215-233, 2012.

GONDIM, S. M. G. Perfil profissional e mercado de trabalho: relação com a formação acadêmica pela perspectiva de estudantes universitários. Estudos de Psicologia 2002, 7(2), 299-309

GUEDES, V.G.F.; DUARTE, E.G. Novos modos de construção do conhecimento: uma reflexão aplicada à organização. Cadernos de Ciência e Tecnologia, Brasília, v.17, n.3, p.83-107, 2000.

INEP. Censo Escolar da Educação Superior 2006. Brasília, DF: Ministério da Educação/Instituto Nacional de Estudos e Pesquisas Educacionais Anísio Teixeira, 2006. Disponível em: $<$ http://portal. inep.gov.br/artigo/-/asset_publisher/B4AQV9zFY7Bv/content/mulheres-sao-maioria-na-educacaosuperior-brasileira/21206>. Acesso em: 02 nov. 2012. [ Links ]

JEZINE, E. A extensão universitária como uma prática social. In: Anais do $7^{\circ}$ Congresso LatinoAmericano de Sociologia Rural, 2006, Quito, Equador. La Cuestión Rural em América Latina: Exclusión y Resistência Social: por un agro com soberanía, democracia y sustentabilidade. Quito (EC); 2006. p. 1-16. . Disponível em: http://www.alasru.org/cdalasru2006/15\%20GT\%20Edineide\%20 Jezine.pdf. Acesso em: 07 nov. 2019.

JODELET, D. Representações sociais: um domínio em expansão. In: JODELET, D. (Org.). As representações sociais. p. 11-44. Rio de Janeiro: EDUERJ, 2001.

LAUDARES, S. S. A.; SILVA, K. G.; BORGES, L. A. C. Cadastro Ambiental Rural: uma análise da nova ferramenta de regularização ambiental no Brasil. Revista Desenvolvimento e Meio Ambiente, Lavras, v. 31, p. 111-122, 2014.

MACHADO, J. A. S. Difusão do conhecimento e inovação: o acesso aberto a publicações científicas. 2005. Disponível em: $<$ http://www.uspleste.usp.br/machado/t_05/acesso_aberto_machado. pdf>. Acesso em: 23 fev. 2012.

MARCONI, M.A.; LAKATOS, E.M. Fundamentos de metodologia científica. 6.ed. São Paulo: Atlas, 2005.

MENDONÇA, A.F.; ROCHA, C.R.R.; NUNES, H.P.; REGINO, S.M. Metodologia Científica: guia para elaboração e apresentação de trabalhos acadêmicos. Goiânia: Faculdades Alves Faria, 2003. 131p. 
PIMENTA, S. G. O Estágio na formação de professores: unidade entre teoria e prática? Cadernos de Pesquisa, n. 94, p. 58 - 73, 1995.

PIRES, M. O. O cadastro Ambiental rural: das origens às perspectivas para a política ambiental. Brasília: Conservação Internacional, 2013.

RAUBER, S.B. Extensão universitária e formação profissional: indissociáveis no processo de aprendizagem da Universidade Católica de Brasília. 2008. Anais eletrônico: VIII Congresso Nacional De Educação Educere Edição Internacional III Congresso Ibero - Americano Sobre Violências Nas Escolas - Ciave. Disponível em: http://www.pucpr.br/eventos/educere/educere2008/anais/pdf/792_883.pdf >. Acesso em: 01 jul. 2010.

SANTANA, A. C. Planejamento estratégico institucional da UFRA: 2014-2024 - Belém, 2015. 17; 25p. Disponível em: https://novo.ufra.edu.br/images/reso_120_1_plain.pdf Acesso em 07 de nov. de 2019.

SANTOS, J. C. F. dos. Aprendizagem Significativa: modalidades de aprendizagem e o papel do professor. Porto Alegre: Mediação, 2008.

SOUSA, I.S.F. A importância do relacionamento pesquisa/extensão para a agropecuária. Cadernos de Difusão Tecnologia, Brasília, v.5, n.1/3, p.63- 76, 1988.

THIOLLENT, M. Anotações críticas sobre difusão de tecnologia e ideologia da modernização. Cadernos de Difusão de Tecnologia, Brasília, v.1, n.1, p.43- 51, jan./abr., 1984.

Recebido em: 22 de junho de 2020 .

Inserido em: 10 de agosto de 2020.

Esta obra está licenciada com uma Licença Creative Commons Atribuição 4.0 Internacional. 